\title{
LSA2L2 Regimen
}

National Cancer Institute

\section{Source}

National Cancer Institute. LSA2L2 Regimen. NCI Thesaurus. Code C161976.

A chemotherapy regimen consisting of an induction phase with cyclophosphamide, daunorubicin, vincristine, prednisone, and intrathecal methotrexate; a consolidation phase with cytarabine, thioguanine, L-asparaginase, carmustine and intrathecal methotrexate; and a maintenance phase with thioguanine, cyclophosphamide, hydroxyurea, daunorubicin, intravenous and oral methotrexate and vincristine that may be used in the treatment of non-Hodgkin lymphoma (NHL). 